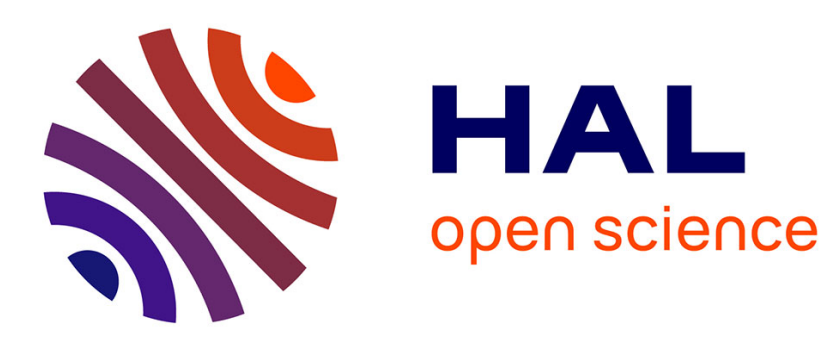

\title{
Cheating, Emotions, and Rationality: An Experiment on Tax Evasion
}

Giorgio Coricelli, Mateus Joffily, Claude Montmarquette, Marie Claire Villeval

\section{To cite this version:}

Giorgio Coricelli, Mateus Joffily, Claude Montmarquette, Marie Claire Villeval. Cheating, Emotions, and Rationality: An Experiment on Tax Evasion. Experimental Economics, 2010, 13 (2), pp.226-247. 10.1007/s10683-010-9237-5 . halshs-00462067

\section{HAL Id: halshs-00462067 https://shs.hal.science/halshs-00462067}

Submitted on 30 Apr 2010

HAL is a multi-disciplinary open access archive for the deposit and dissemination of scientific research documents, whether they are published or not. The documents may come from teaching and research institutions in France or abroad, or from public or private research centers.
L'archive ouverte pluridisciplinaire HAL, est destinée au dépôt et à la diffusion de documents scientifiques de niveau recherche, publiés ou non, émanant des établissements d'enseignement et de recherche français ou étrangers, des laboratoires publics ou privés. 


\title{
Cheating, Emotions, and Rationality: An Experiment on Tax Evasion
}

\author{
Giorgio Coricelli*, Mateus Joffily", \\ Claude Montmarquette ${ }^{\S}$, Marie Claire Villeval ${ }^{\diamond}$
}

\begin{abstract}
The economics-of-crime approach usually ignores the emotional cost and benefit of cheating. In this paper, we investigate the relationships between emotions, deception, and rational decision-making by means of an experiment on tax evasion. Emotions are measured by skin conductance responses and self-reports. We show that the intensity of anticipated and anticipatory emotions before reporting positively correlates with both the decision to cheat and the proportion of evaded income. The experienced emotional arousal after an audit increases with the monetary sanctions and the arousal is even stronger when the evader's picture is publicly displayed. We also find that the risk of a public exposure of deception deters evasion whereas the amount of fines encourages evasion. These results suggest that an audit policy that strengthens the emotional dimension of cheating favors compliance.
\end{abstract}

Keywords: Deception, tax evasion, emotions, physiological measures, experiment.

JEL Classifications: C91, C92, D87, H26

\footnotetext{
${ }^{*}$ CNRS, Centre de neurosciences cognitives, 67, boulevard Pinel 69675 BRON Cedex, France. E-mail: coricelli@isc.cnrs.fr

\# IPUB, Federal University of Rio de Janeiro, Av. Venceslau Brás, 71, 22290-140, Rio de Janeiro, Brazil; CNRS, Centre de neurosciences cognitives, BRON, France. E-mail: joffily@isc.cnrs.fr

$\S$ CIRANO, Université de Montréal, 2020 University Street, Montreal (Quebec), Canada, H3A 2A5. E-mail: Claude.Montmarquette@cirano.qc.ca

${ }^{\diamond}$ Université de Lyon, Lyon, F-69007, France; CNRS, GATE, 93, Chemin de Mouilles Ecully, F-69130, France; IZA and CCP. E-mail: villeval@gate.cnrs.fr

Referees' comments were very useful in revising the paper. The authors are also grateful to participants at the ESA World Meeting in Rome, at the Workshop on Risk Attitude in Montpellier, and at seminars at the University of California at Santa Barbara, at the Universities of Aarhus, Copenhagen, and Liege, and at the WZB in Berlin for their comments and suggestions. We thank R. Zeiliger for programming the experiment. This research was supported by a grant from the Rhône-Alpes Region (CIBLE program).
} 


\section{INTRODUCTION}

Many situations involve deception, like plagiarism, embellished résumés, or trickery in sports. Recent scandals at Enron, for example, remind us that cheating in markets is not unusual (Gerschlager, 2005). Tax evasion and social fraud provide other examples of substantial deception by economic agents (Slemrod, 2007). The standard economics-of-crime approach explains deception as resulting from a comparison between the expected benefit and cost of cheating. The cost of cheating is however restricted to the monetary consequences of detection, and the cost of the very act of cheating is neglected. Yet, recent studies have provided some evidence of lie or guilt aversion (Gneezy, 2005; Charness and Dufwenberg, 2006; Sanchez-Pages and Vorsatz, 2007). Regarding tax evasion, if empirical studies confirm the basic mechanisms of the deterrence models (Allingham and Sandmo, 1972, and Yitzhaki, 1974), they also reveal that some people comply although the benefits of cheating clearly outweigh its monetary cost (See Alm, 1991, Andreoni et al., 1998, Cowell, 1990, and Slemrod, 2007, for surveys). This has motivated the exploration of other dimensions of tax compliance, like tax morale, social norms (Slemrod, 1998; Torgler, 2007; Kirchler, 2007), ethics (Blumenthal et al., 2001), or conformity (Myles and Naylor, 1996; Fortin et al., 2007). We adopt a complementary approach by investigating the influence of emotions on cheating behavior with an application to tax evasion. Economists have not widely explored yet the role of emotions in cheating behavior. We aim at contributing to fill this gap. ${ }^{1}$

We claim that both the cognitive deliberation preceding income reporting and the realization of an audit, possibly followed by sanctions, involves emotions. We

\footnotetext{
${ }^{1}$ Although Bentham early incorporated emotions in his theory of utility, economists have only recently studied the role of emotions in decision-making (Elster, 1996, Loewenstein, 2000). They have identified their influence on reciprocity (Ben-Shakhar et al., 2007), punishment (de Quervain et al., 2004), or investment decisions (van Winden et al., 2008).
} 
assume that emotions associated with reporting, audit, and sanctions inform and influence the agents' deliberation and therefore, constitute a driving force of behavior. Various emotions might be related to compliance or evasion. ${ }^{2}$ Individuals might experience both anticipatory emotions when evaluating the risk associated with underreporting and anticipated emotions when anticipating how bad they will feel if audited and punished and how good and relieved if not audited. ${ }^{3}$

We also expect that, ex post, the detection of cheating raises emotions which intensity is increased when deception is made public. In particular, detected evaders may feel regret and guilt even when the information is not spread out and shame if their cheating behavior is made public. ${ }^{4}$ This is at least what the authorities expect when they publicly expose the offenders. ${ }^{5}$ Since it is difficult to cope with a damaged reputation, shame avoidance might have a larger impact on future compliance than its private counterpart (on such amplification effect, see Kahneman and Miller, 1986).

Our paper is original in that our laboratory experiment links economic behavior in an income-reporting game to physiological measures of emotions and self-reports of emotions. In our benchmark treatment, each subject receives an income that is taxed at a proportional rate. He has to decide how much income he is willing to report. He faces a probability to be audited, in which case he must pay a penalty for underreporting. The picture treatment follows the same rules except that an

\footnotetext{
${ }^{2}$ When the product of the tax is used for a charitable cause, Harbaugh et al. (2007) show that mandatory taxation entails neural activity in brain areas that are related to rewards.

${ }^{3}$ As defined by Loewenstein et al. (2001): "Anticipatory emotions are immediate visceral reactions to risks and uncertainties. Anticipated emotions are typically not experienced in the immediate present but are expected to be experienced in the future... anticipated emotions are a component of the expected consequences of a decision..." (p. 268).

${ }^{4}$ Interestingly, Allingham and Sandmo (1972) explicitly mention that tax evasion may be limited if the individuals fear losing their reputation, but do not include this consideration in their model. In psychology, see Seiter and Bruschke (2007) on the role of guilt and shame in deception.

${ }^{5}$ While pillories have been used in many cultures, the Web provides, nowadays, many examples of such policies. For example, the Chicago police department displays the pictures and home addresses of arrested prostitute patrons; a listing of convicted pedophiles is available in every state in the U.S.A.; the government of Canada displays the names of citizens convicted of fiscal fraud. We have not found any empirical estimation of their efficiency.
} 
individual's cheating behavior is publicly revealed through the public display of his picture. This allows us to differentiate the impact of monetary versus non-monetary sanctions by holding the expected monetary return of evasion constant.

To measure the emotional arousal associated with the reporting decisions and the feedback on audits, we record the subjects' Skin Conductance Responses (SCR) (Bradley, 2000). The SCR is a phasic component of the electrodermal activity primarily controlled by the sympathetic division of the autonomic nervous system (Dawson et al., 2000). It is associated to emotional arousal in a wide range of psychological states and processes (Boucsein, 1992). We also use affective selfreports to assess the emotional arousal (low-high intensity) and the hedonic valence (pleasant-unpleasant) dimensions of emotions as a robustness check and as a complement. ${ }^{6}$ Indeed, research in psychology has shown that emotional arousal and valence can explain most of the variance in emotions (Russel and Mehrabian, 1974; Lang et al., 1992; Anders et al., 2004). An additional originality of our experiment is that we elicit emotions in a group context.

Our experiment delivers several major findings. Subjects who express increased SCR, i.e. higher anticipated and anticipatory emotional arousal, are more likely to evade and evade more. Emotional arousal at the time of audit is increased by the prospect of additional earnings and the avoidance of certain losses, and also by monetary and non-monetary sanctions. These results show that, despite the sterility of the environment, it is possible to capture emotions and the fear of social stigma in the laboratory. Indeed, being in an environment where the picture of the detected evader is publicly displayed raises more emotions in case of an audit and deters cheating. In

\footnotetext{
${ }^{6}$ Self-reports on the emotional valence and arousal dimensions are correlated with autonomic and somatic responses to emotional stimuli, while SCR positively correlate with the emotional arousal independently of valence (Bradley and Lang, 2001)
} 
contrast, while being audited raises emotions and reduces the extent of evasion in the following period, the higher the fine the higher the proportion of evaded income. As Baldry (1986) has shown that tax evasion is not a gamble because it involves moral considerations, our findings strongly support the analyses on the importance of tax morale. People do not only feel anxiety because of the monetary prospects of a risky decision but also due to the moral implications associated with the risk of a public exposure of their behavior. This is a major finding because it suggests that a tax authority could better discourage evasion by increasing the emotional cost of evasion.

The remainder of this paper is organized as follows. Section 2 develops the experimental design and the predictions. Section 3 analyzes the results. Section 4 discusses the results and concludes.

\section{THE EXPERIMENT}

\section{A. Experimental design}

Two treatments. The benchmark treatment involves a group of eight players who receive an individual income $I$, with $I \in\{50,100,150,200\}$. Each income level is randomly assigned to two subjects in each period, but this is not common information. The players are requested to report their income that will be taxed at a uniform tax rate of $55 \%$, by means of a scrollbar of which maximum graduation corresponds to the subject's actual income. To produce a stronger test of social emotions, we do not redistribute the tax funds to the subjects who are informed that these paybacks will go into research funds for other experiments. ${ }^{7}$

\footnotetext{
${ }^{7}$ We acknowledge that we do not know the subjects' valuation of the taxes and fines collected that may be considered as a specific form of a public good. The subjects do not, however, benefit from these funds directly. If this procedure has nevertheless influenced decisions, in one way or the others, there is no reason to believe that the subjects' reaction will be different between treatments since we use a within-subject design.
} 
The players know that their reported income can be audited according to a certain cutoff audit scheme and that this audit will entail the payment of a fine if the reported income is less than the actual income. The realism of the design has been strengthened by replicating the structure of income reporting, by using non-neutral terms in the instructions so that it makes no doubt that underreporting means cheating, ${ }^{8}$ and by introducing an endogenous audit rule. The probability of an audit is endogenous in that it depends on the median report in the group, and this is made common information. ${ }^{9}$ If the reported income of a player is among the four highest reported incomes in the group, his audit probability is $35 \%$. If his reported income is among the four lowest reported incomes, his audit probability is $65 \%$. If all subjects report the same amount, the probability is uniform and equal to $50 \% .{ }^{10}$ The reason why low-reported-income players have a higher probability of being audited is because reporting low incomes signals to the tax authority, which knows the distribution of income but not each individual's income, that the individual might have underreported by a substantial amount. The tax authority has less to gain in auditing high reported incomes. Another reason for this endogenous scheme is that one's own evasion decreases the risk of audit of the other subjects (which is realistic since the auditing resources of the tax administration are constrained); therefore

\footnotetext{
${ }^{8}$ Using loaded terms loses some control over the subjects' preferences; on the other hand, it introduces context that makes mental scripts less necessary (Alm, 1991). Alm, McClelland and Schulze (1992) compare two experiments using either loaded or neutral wording and find no difference in behavior. ${ }^{9}$ In real settings, the probability of an audit depends on the taxpayer's decisions since reports convey information. While empirical analyses are plagued by such an endogeneity problem (Alm, 1991), experiments allow clearing it up by using random audit probabilities. Most experiments, however, do not analyze how endogenous probabilities influence decisions. Exceptions are Collins and Plumlee (1991), Alm et al. (1993), Cason and Gangadharan (2006), Cummings et al. (2009).

${ }^{10}$ These probabilities are above the usual enforcement levels in order to collect enough detection observations. Note that one can also find high rates in reality, for example against taxpayers who have been caught in the past or in the presence of cutoff rules such that a report lower than some cutoff level will be audited with certainty (see Torgler, 2007). Again, we create an environment hostile to the phenomenon we want to study since we suspect that frequent detection erodes the emotions associated with cheating, due to a habituation effect (Dawson et al. 2000). And this is what we observe in this experiment (see below).
} 
evading taxes does not hurt the group members. While creating some interdependencies between the subjects, this auditing rule is hostile to the emergence of a social stigma and provides a stronger test of social emotions (see below). The subjects are not informed on their individual audit probability (see Spicer and Thomas, 1982, and Alm, Jackson, and McKee, 1992, on the impact of uncertain audit probabilities on compliance). They do not receive any feedback on others' behavior. ${ }^{11}$

If the player is not audited, his net income corresponds to his gross income minus the tax on his reported income. If an audit concludes to underreporting, both the tax on the actual income and a fine are charged. As in Yitzhaki (1974), the fine is proportional to the unpaid taxes; it is fixed at $20 \%$, which is a realistic value (Andreoni et al., 1998).

The picture treatment follows the same rules as the benchmark. The only difference is that if an audit reveals that a player has underreported his income, his picture is displayed on his own screen and on the screens of other taxpayers. This treatment aims at identifying whether public information on one's own cheating involves additional emotions leading to more compliance. ${ }^{12}$ In a period, only one picture can be displayed on the screen of any subject; if more than one cheater have been audited, there is a random display of each picture on the screen of the non-audited subjects and

\footnotetext{
11 An endogenous audit mechanism raises the possibility of potential coordination among participants. However, Alm and McKee (2004) have shown in their experiment that individuals find it difficult to coordinate on the zero-compliance equilibrium. Our endogenous audit rule depending on the median income report of the group of eight players makes this coordination even more difficult given that the game has no Nash equilibrium in pure strategies as discussed below.

${ }^{12}$ If subjects perceive the environment as one about cheating the experimenter rather than the group members (because tax funds are used for further research or because one's own evasion reduces the audit probability of others), this treatment should not have a strong emotional or behavioral impact, especially since cheating the experimenter could be considered as acceptable from students who need money.
} 
the honest audited taxpayers. ${ }^{13}$ The amount evaded by a cheater is not displayed since it could be an additional source of influence on individual decisions.

We used a within-subject design to keep the subjects' characteristics constant and increase statistical power. The sessions consisted of 30 periods, divided into six blocks of five periods. The benchmark treatment was implemented in periods 1 to 5 , 11 to 15,21 to 25 , and the picture treatment in the remaining periods.

Eliciting risk attitude. A parsimonious procedure (see Charness and Gneezy, 2003) has been used in the preliminary part of the experiment to elicit the individual degree of risk aversion. Each subject was endowed with 15 points (his show-up fee of $€ 3$ ) and had to decide how much to invest in a risky asset and how much to keep. In case it fails, the amount invested is lost; in case of a success, the investment returns 2.5 times its amount. Each subject had also to choose one of two colors. If this color is randomly drawn at the end of the session, with a $50 \%$ chance, the investment is a success. A risk-neutral subject should invest his full endowment. The lower the amount invested, the higher the degree of risk aversion.

The "Physionomics lab" and the self-reports. We proceeded to the simultaneous and continuous electrophysiological (Skin Conductance Responses) recording of groups of eight interactive subjects until the end of the sessions. Indeed, the literature in psychology and neurophysiology has established that SCR capture emotional arousal (Bradley et al., 2001). ${ }^{14}$ The method is exposed in details in Appendix 1. The SCR have been analyzed for the decision and the feedback on audit.

\footnotetext{
${ }^{13}$ Displaying only one picture at a time does not allow the subjects to identify the number of evaders in the session. A subject who is caught cheating does not know if there were other cheaters and how many subjects can see his picture.

${ }^{14}$ A connection between SCR generation and the brain areas involved on higher stages of information processing (e.g. information uptake, decision and storage processes) has also been evidenced. However, the role of SCR as an indicator of cognitive effort is not clearly defined, probably due to the wide variety of theoretical and experimental approaches used (Boucsein, 1992).
} 
In addition, at the end of each period, the subjects had to report their feelings at the moment of the audit by means of two 7-point Likert-type scales of emotional arousal (from extremely weak to extremely strong) and hedonic valence (from extremely negative to extremely positive). Indeed, an adequate assessment of emotions requires an integration of behavior, verbal report and physiology (Bradley and Lang, 2001). While the physiological measures provide an autonomic measure of the subject's emotional arousal, the self-reports unveil, backwardly, the subjective intensity and direction of emotions experienced by the subjects. Last, at the end of the session, we administered an attitudinal questionnaire on fraud. ${ }^{15}$

The subjects' payment consisted of the average earnings in two randomly selected periods in order to avoid possible wealth effects. The instructions specified that a person who is not aware of the content of the experiment would pay the subjects in private in a different room; this was done to limit accountability.

\section{B. Predictions}

The predictions of this game in the vein of Allingham and Sandmo (1972) and Yitzhaki (1974) are the same for both treatments if players are rational. We assume that the utility function of the participants is linear in income. The expected gross income, $\mathrm{I}$, is 125 . For the symmetry of the game, we assume that each player believes that the others receive the same income with equal probability. The probability to be audited, assuming that each player uses the same strategy, is $p=0.5^{*} A_{\text {Low }}+$ $0.5 * \mathrm{~A}_{\text {High, }}$ with $\mathrm{A}_{\text {Low }}\left(\mathrm{A}_{\text {High }}\right)$ being the audit rate for those reporting income below

\footnotetext{
${ }^{15}$ Note that the self-reports do not inform more than SCR measures on the very nature of emotions (anger, guilt, ...). An alternative would have been to ask the subjects to report the intensity of each of various possible feelings at the end of each period. But in addition to be time-consuming and boring, this could have focused too artificially the subjects' attention on emotions. In the attitudinal questionnaire, the subjects had to report on a 7-point Likert-type scale their feelings (from extremely negative to extremely positive) regarding tax evasion by shopkeepers, fare-dodging, and offences against the Highway Code.
} 
(above) the median. Let $\mathrm{t}$ be the tax rate and $\mathrm{f}$ the penalty rate. If an individual reports an amount $\mathrm{R}$ of his gross income I, his expected net income, ENI, is:

$$
I-[p(t I+f t(I-R))+t(1-p) R]=E N I
$$

If an individual reports his full income, then his net income, NI, is: $I-t I=N I$

The expected rate of return from reporting no income relatively to full income is:

$$
\frac{E N I(\text { with } R=0)-N I}{N I}=\frac{t(-p(1+f)+1)}{1-t}
$$

With the following parameters, $t=55 \%, f=20 \%, A_{\text {Low }}=65 \%$ and $A_{\text {High }}=35 \%(p=$ $50 \%$ ), the expected rate of return is $45 \%$. Full reporting is therefore a dominated strategy. In addition, a subject may realize that it is easier to hide evasion when one receives a high income if he believes that other subjects have drawn a lower income.

The game has no Nash equilibrium in pure strategies and the solution is a mixed strategy equilibrium with a positive compliance rate because a subject has always an incentive to deviate by reporting one unit more than the others to reduce his own audit probability to $35 \%$. The equilibrium cannot be easily characterized, but it should be similar in both treatments. ${ }^{16}$ However, the high expected return from evasion let us suppose that theoretical compliance should be low.

In addition to risk aversion, anticipatory and anticipated emotions may lead players to comply more if the positive emotions raised by evasion, such as excitement due to the prospect of higher payoff, are outweighed by the expected psychic cost of being caught cheating. The only reason why we could observe different decisions and patterns of SCR in the picture treatment than in the benchmark is that additional negative emotions may arouse from the anticipation of seeing one's own picture or

\footnotetext{
${ }^{16}$ We cannot characterize the mixed strategy equilibrium because we use endogenous audit probabilities. In the picture treatment players get to know other players through the dissemination of pictures. We do not believe however that the game should be considered as a repeated game since only one picture can be disseminated in one period and not all group members evade.
} 
others' pictures disseminated in the group although cheating generates positive externalities on others.

\section{Experimental procedures}

The experiment consisted of six sessions. These sessions were conducted at the Groupe d'Analyse et de Théorie Economique (GATE), Lyon, France. 48 subjects (of which $63 \%$ were males), eight for each session, were recruited from undergraduate courses in the local business and engineering schools using the ORSEE software (Greiner, 2004). All of the subjects were inexperienced in this type of experiment. The experiment was computerized using the REGATE software (Zeiliger (2000)).

Upon arrival, the subjects drew a tag indicating their randomly designated computer. They were asked whether they allowed us to take a picture of their face and to do physiological recording (all have accepted). It was made explicit that this picture would be used at some point during the experiment, that they would be informed before the possible use of the picture, and that they could quit immediately against the payment of the show-up fee. They were guaranteed that their picture would be immediately destroyed at the end of the session and that they could attend the destruction. The volunteers were required to keep a neutral face when we took their picture since studies in psychiatry show that emotions expressed on pictures may be contagious (Wild, 2003). Next, after washing their hands with a neutral soap for a better skin conductance, the subjects sat down in front of their computer. The electrodemal electrodes filled with neutral-base paste were placed on the fingers of their non-dominant hand. The electrodermal signal was then monitored and we proceeded to any adjustment required. Concomitantly, the instructions for the preliminary part of the experiment were read aloud (Appendix 2). At the end of the questions answering (in private), more than five minutes from the placement of the 
last electrodes had elapsed, allowing time for the paste to be absorbed by the skin and the electrodes to make good contact. After the completion of the test of risk attitude, the instructions for the other parts were distributed and read aloud. For the sake of realism, the instructions used tax-specific language but they avoided loaded terms such as 'cheating' or 'lying'. We checked the understanding of the rules by means of a questionnaire. During each period, to avoid any overlapping between different sources of emotions, we imposed a fixed duration to some events (12 seconds after the feedback on audit, 6.5 seconds after the picture display, 3 seconds after the feedback on payoffs), while decisions and affective self-reports were self-paced.

At the end of the session, the subjects answered to the attitudinal questionnaire on fraud and to demographic questions, and they drew the color that determined whether their initial investment was a success or not. On average, a session lasted 75 minutes, including preparation of the subjects for the physiological recording and cash payment. The subjects received a show-up fee of $€ 3$ and earned $€ 19.33$ on average.

\section{RESULTS}

Overall, we find substantial treatment effects, as an environment where evading behavior is made public reduces the proportion of evaders and the amount evaded. Emotional arousal correlates with cheating behavior and punishment, especially when made public. We provide descriptive statistics before considering the determinants of cheating behavior and the reactions to being audited.

\section{A. Summary statistics and non-parametric analysis}

Table 1 displays some descriptive statistics.

(Table 1 about here) 
Table 1 indicates first that the proportion of evaders increases with income (all pairwise comparisons indicate that the differences are significant at the $5 \%$ level). ${ }^{17}$ Second, the level of income exerts a non-linear influence on the proportion of evaded income in evaders. ${ }^{18}$ Third, the proportion of evaders is marginally lower in the picture treatment than in the benchmark $(p=0.078)$, especially when incomes are either 50 (with a borderline $\mathrm{p}$-value of $p=0.108)$ or $100(p=0.089)$. In contrast, the proportion of evaded income is higher in the picture treatment than in the benchmark for incomes of 50 or 100 and lower for higher incomes (but the Mann-Whitney tests fail concluding on significant differences). This suggests the existence of a selection effect: the subjects who care most about social sanctions do not evade when it is more risky to do so and those who take this higher risk do it for a higher proportion of income.

Regarding emotions, Table 1 shows that the average SCR amplitude is higher when people underreport than when they comply (Wilcoxon test: $p=0.028$ ). It is twice as high when related to the reporting decision and three times higher when related to the feedback on audit. Higher SCR are associated with more evasion. In the benchmark, the average SCR amplitude at the time of decision is 0.11 for the subjects who evade less than $25 \%$ of their income; it rises to 0.17 when they evade between $25 \%$ and $49 \%$ of their income and to 0.22 when they evade between $50 \%$ and $74 \%$, and $75 \%$ or more. In the picture treatment, the corresponding values are $0.10,0.20,0.26$, and

\footnotetext{
${ }^{17}$ In all the reported non-parametric statistics, a session gives one independent observation and all tests are two-sided. Mann-Whitney tests indicate that the proportion of evaders when the income is 200 is significantly higher than when the income is $150(p=0.034), 100(p=0.028)$ and $50(p=0.028)$. This proportion when the income is 150 is significantly higher than when the income is $100(p=0.046)$ and $50(p=0.028)$. It is also significantly higher when the income is 100 than when it is $50(p=0.034)$.

${ }^{18}$ According to Wilcoxon signed-rank tests, the evaders dissimulate a higher proportion of their income when they earn 50 than when they earn $100(p=0.028), 150(p=0.027)$, or $200(p=0.028)$. On the other hand, the average proportion of evaded income is significantly higher when evaders receive an income of 200 than when their income is $150(p=0.046)$.
} 
0.19 , respectively. ${ }^{19}$ For the subjects evading between $25 \%$ and $74 \%$ of their income, the picture treatment is significantly more arousing than the other treatment (MannWhitney tests: $p=0.037$ for the SCR measured at the time of decision, and $p=0.004$ for the SCR measured at the time of audit). In this treatment, when the subjects evade $75 \%$ of their income or more, the SCR is, however, not higher than when they evade between $50 \%$ and $74 \%$ (Mann-Whitney test, $p>0.10$ ). The people who report nothing in this environment are more likely to experience less psychic cost in cheating; or perhaps knowing they will feel bad if detected, they are better evading totally than a fraction of income. This may explain why the average SCRs, both at the time of decision and audit, do not differ much by treatment in Table 1 (MannWhitney tests, $p>0.10)$.

To summarize, we find that there are marginally less evaders in the picture treatment than in the benchmark and that the average SCR amplitude is higher when people evade taxes than when they comply.

\section{B. Determinants of the evasion decision}

It is expected that the decision to evade and the amount of taxes unreported can be explained by different variables and by differential effects of the same variables affecting both decisions. In a panel setting, we will deal with this situation by referring to a two-step generalized Tobit model.

Table 2 displays the results of this estimation procedure. First we estimate the determinants of the decision to evade taxes by means of a random-effects Probit model (column 1). We include individual random effects to control for the lack of independence between each trial since each individual is observed 30 times. This is

\footnotetext{
${ }^{19}$ At the time of audit, the corresponding values in the benchmark treatment are $0.08,0.13,0.17$, and 0.21 ; in the picture treatment, they are $0.07,0.18,0.20$, and 0.18 , respectively.
} 
confirmed by the significant value of the $\rho$ coefficient. The independent variables include each income value (the minimum income being the omitted reference category), the picture treatment, and a time trend. They also include individual characteristics such as the subject's SCR amplitude before the decision is entered, this variable interacted with the picture treatment, the subject's gender, his/her age, the decision time and its squared value (that may indicate the depth of reasoning), and the amount invested in the lottery.

We consider SCR amplitude as an exogenous variable and not as a consequence of the cheating decision. Indeed, we assume that emotions consist of anticipatory and anticipated responses and they are used as a source of information in the decisionmaking process, as stated by Loewenstein et al. (2001) - see also Zajonc (1984) on the primacy of affect. Furthermore, emotional arousal is measured before the subject submits his report. ${ }^{20}$

In the second step, we estimate two models of the proportion of evaded income by means of random-effects GLS models with robust standard errors. In column 2 of Table 2, we add to the regressors the inverse of the Mill's ratio extracted from the first-step estimation (à la Heckman) to control for a potential correlation among the error terms of the two equations. $^{21}$ In column 3 , we include individual time-invariant characteristics such as opinion on various types of fraud, mother's education (equal to 1 if the mother went to University), and existence of a loan to pay tuition fees as a

\footnotetext{
${ }^{20}$ Studies in psychology on decision-making support a three-stage model: (1) stimulus detection, (2) central processing and (3) motor execution. Miller and Low (2001) showed that the duration of motor execution stage is invariant across different reaction time tasks and its mean duration is around $200 \mathrm{~ms}$. The stimulus detection's duration is also recognized as invariant within the same task, leading to the conclusion that duration variability across trials is ultimately due to differences at the central processing stage. In our experiment, both stimulus detection (income display) and motor execution (income reporting) procedures were kept constant across trials. Thus, we interpret the whole interval between stimulus detection and motor execution as part of the decision making process itself.

${ }^{21}$ The variables used in the regressions were dictated by the literature and to achieve identification of the parameters to be estimated.
} 
proxy for the individual's wealth. ${ }^{22}$ We also control for the first underreporting, for an audit in the previous period and the amount of the fine, if any. ${ }^{23}$

(Table 2 about here)

The decision to evade equation shows first that the likelihood of evading taxes increases directly in the level of income. A second major finding is that an environment where deception is made public favors tax compliance relative to an environment where fraud is only punished by monetary sanctions. Ceteris paribus, the risk of non-monetary sanctions diminishes by $8.2 \%$ the probability to evade taxes. This effect would have been probably even larger if we had directly redistributed the product of taxes among the subjects or in the absence of positive audit externalities. A third major result is that the SCR amplitude measured before the decision is made has a marginal positive influence on evasion (with no additional treatment effect). The more subjects are emotionally aroused, the more they choose to evade. The marginal effect of one SCR point is $13.9 \%$ (note that SCR values are distributed between 0 and 2.24). In contrast, a subject who rejects the idea of cheating decides straight away to comply without experiencing a significant level of emotions.

The decision to evade taxes is also associated, although non linearly, with a longer decision time (the compliers decide in 9.25 seconds on average while the evaders' decision takes 12.42 seconds). This could be associated with both the higher cognitive requirement involved in the decision to evade taxes if the subject elaborates mixed strategies and a possible tension between the expected payoff of underreporting

\footnotetext{
${ }^{22}$ Asking direct questions on individual resources is not a better alternative since almost no subject is working while studying. Asking about the parents' income is not better because some students are reluctant to report this information or are simply not well informed.

${ }^{23}$ These lagged variables are not included in model 1 because this equation is better estimated on the full sample of observations since emotional arousal is stronger at the beginning of the game. In addition, it could have introduced an endogeneity bias since being fined in the previous period is directly associated with the decision to evade. We have omitted the insignificant lagged audit variable.
} 
and the emotional consequences of violating the social norm of non-cheating. Indeed, a higher decision time may be correlated with both a higher cognitive activity and a higher emotional arousal (contrary to what is suggested by Rubinstein, 2007).

Columns 2 and 3 in Table 2 show that conditional on the decision to evade, the picture treatment exerts a strong negative effect on the proportion evaded $(-3.466$ points) while the higher the SCR, the higher the proportion evaded (with no additional effect of the treatment). This behavior is probably emotionally driven since the dissemination of pictures in case of detection is not related to the importance of fraud. The proportion of evaded income is significantly lower when income is higher than 50 although the relationship is not linear. This higher evasion when income is low could result from the subjects having a reference level of income below which they are willing to take a higher risk of audit for avoiding the pain associated to a certain loss in case of compliance (see Bernasconi and Zanardi, 2004, and Dhami and AlNowaihi, 2007, for an application of cumulative prospect theory to tax evasion). In contrast with the decision to evade taxes, the decision time has a negative effect; indeed, those who decide to evade their income in full decide more quickly (8.69 seconds instead of 13.14 for those who do not fully evade).

In addition to a marginal reduction of the proportion of evaded income over time, the model in column 3 indicates that whereas being audited in the previous period reduces evasion weakly, the amount of the fine exerts the opposite effect. Individuals probably attempt to regain the previous loss by evading more in the current period, which is also consistent with the reference income dependence. People evade less when they underreport for the first time but this is significant at the $5 \%$ level only if this variable is included in model 2 (non reported regression) because this usually happens in the first period of the game while this period is eliminated from the third 
regression. A higher amount invested in the risky asset in the preliminary part of the experiment is associated with a higher proportion of evaded income, but significantly so only when we control for auditing in the previous period. Males are not more likely to evade taxes than females but when they do, they dissimulate a higher proportion of income (which is consistent with the literature, see Slemrod, 2007). Having a mother with a university education reduces the proportion evaded, perhaps through the transmission of norms. Having to reimburse a loan has a positive impact on evasion. Lastly, a more negative opinion regarding drivers contriving the Highway Code is significantly correlated with less evasion, while a negative opinion on fare dodgers came short of significance $(p=0.116)$. Variables such as the number of times a subject can see his own picture or the picture of other group members are not significant and are omitted. Last, the inverse of the Mill's ratios are insignificant.

To summarize, an environment where deception is made public increases compliance and reduces the proportion of evaded taxes relative to a policy using only monetary sanctions. We also find that a higher emotional arousal predicts more evasion and that if being audited in the previous period slightly reduces evasion, the amount of the fine increases it.

\section{Reactions to an audit}

We now focus on the determinants of the physiological SCR amplitude and selfreported feelings when people receive a feedback on audits. Indeed, the self-reports that have been collected at the end of each period regarding audit offer a robustness check and a complement to our analysis of physiological measures since the SCR measures cannot indicate the direction of emotions. Table 1 has shown that the average self-reported emotional arousal, measured on a scale from 1 (extremely weak) to 7 (extremely strong), was higher for tax evaders (4.20) than for non-evaders (3.11). 
This corroborates the SCR measures ( 0.16 and 0.05 , respectively). Similarly, evaders report less positive hedonic valence regarding the audit (3.84) than non-evaders (4.27), on a scale from 1 (extremely negative) to 7 (extremely positive). In addition, the correlation coefficient between the SCR amplitude at the time of the audit and the self-reported arousal is significant and equal to 0.54 .

Three econometric models have been estimated to identify the determinants of emotional reactions to a feedback on audit. Model 1 is a random-effects Tobit model in which the dependent variable is the SCR amplitude at the time of the audit. Models 2 and 3 are ordered Probit models with robust standard errors and clustering at the individual level in which the dependent variables are the self-reported emotional arousal and the hedonic valence of feelings, respectively. The independent variables comprise a time trend, the proportion of evaded income, and a dummy variable for the first evasion. We also include a dummy variable for the first audit, the amount of the fine, the display of the subject's own picture, the first time the subject's picture is displayed, the current number of times the subject's picture has been displayed since the beginning of the game. Overall we expect that being sanctioned should increase emotional arousal and should exert a negative impact on hedonic valence while not being caught should raise positive emotions. The results are reported in Table 3.

(Table 3 about here)

The SCR amplitude indicates that the emotional arousal increases marginally in the degree of tax evasion when the subject receives a feedback on audit; this feeling is however not self-reported. Other things equal, this could capture the emotional effect of a higher expected payoff. The SCR amplitude is also higher when a subject evades for the first time although the self-reported intensity of feelings indicates the opposite. Reported feelings are more negative when subjects evade for the first time, possibly 
due to guilt. They become more intense and more and more positive over time, possibly because of a dissipation of guilt.

The first time a subject is audited also raises significantly more emotions. An evader who is not audited is also emotionally aroused. Since this is associated with a higher hedonic valence, this could be due to relief and the pleasure due to the avoidance of a loss. Indeed, the average hedonic valence is 5.23 (3.94) for the evaders (compliers) who have not been audited and 2.49 (4.59) when they have been audited. Accordingly, a regression conducted on the sole compliers (not reported here) shows that being audited generates significant positive feelings.

A major finding is related to the consequences of both monetary and non-monetary sanctions on emotions, with almost all of these effects being significant at the $1 \%$ level. The higher the fine, the more the subject is emotionally aroused, and the more he expresses negative feelings, probably related to regret and anger. Moreover, when the evader learns that his picture is going to be disseminated, his emotional arousal further increases (with an additional first-time effect on the SCR amplitude), although this effect tends to diminish with repetition. ${ }^{24}$ This is associated with more negative feelings, possibly related to shame; this interpretation is reinforced by the significant negative coefficient associated with the current number of times a subject has seen his picture disseminated, with no stronger effect of the first time his picture is displayed.

These self-reports should be taken with caution however since the statistical power of the regressions is relatively low, especially in model 2. In addition, due to their

\footnotetext{
${ }^{24}$ We have estimated the effect of seeing the pictures of other group members only on the selfreported intensity and valence of feelings since self-reports are made at the end of each period (not reported here). The display of another's picture has no impact on the emotional arousal but it is associated with positive feelings. These feelings may capture a subject's satisfaction of not having been audited himself if he evaded taxes, or his pleasure of seeing a cheater being caught if he complied. We cannot test this effect on SCR since at the time of the audit, the subjects do not know yet whether another group member has been caught.
} 
subjective nature, they may be biased. Physiological measures, that the subjects cannot easily control, are potentially more reliable. We also acknowledge that we only capture here the direction of emotions but not their nature. Overall, the results show nevertheless a large consistency between the SCR measures, the self-reported intensity and valence of feelings, and our behavioral predictions.

To summarize, the higher the evasion, the higher the SCR magnitude when receiving a feedback on audit. The higher the fine, the more subjects are emotionally aroused, and the more negative are their feelings. This emotional arousal further increases when the evaders learn that their behavior will be exposed publicly. ${ }^{25}$

\section{DISCUSSION AND CONCLUSION}

Deception may generate anticipatory emotions related to the risk of being detected and anticipated emotions related to both moral considerations and the prospect of higher monetary payoffs associated with cheating. Tax evasion constitutes an archetypical example of deception by the economic agents. This paper explores a complementary avenue to the standard deterrence models of tax evasion by testing the hypothesis that the prospect of evading taxes generates emotions in the individuals, which affect their actual behavior, especially when deception can be made public. We link individual behavior both to Skin Conductance Responses that provide a physiological measure of the emotional arousal uncontrolled by the individuals and to affective self-reports that inform on the valence and intensity of emotions.

\footnotetext{
25 As suggest by a referee, exposing the amount not reported or in terms of the percentage of income not reported along with the picture of the participant caught underreporting his income will have added a nice feature to this research in terms of policy issue. Interestingly, Halla and Schneider (2009) based on a large micro data set of respondents from 29 OECD member countries suggest that moral values evolve endogenously and are determined by prices (i.e. the cost of acting morally). The picture treatment definitively affects the real price of cheating.
} 
Our results are striking. We provide the first evidence that cheating is correlated with the emotional arousal of the subjects before submitting their decision. A higher emotional arousal is positively associated with both the likelihood of tax evasion and the amount evaded, indicating that this decision does not only result from the "cold" comparison between the monetary benefits and costs of evading taxes (without mentioning the social benefits that the subjects may derive from future research funding through taxes). The cognitive deliberation involves "hot" processes activated by the emotional brain. The subjects who comply are those who do not experience such emotions and they decide more quickly than evaders. Our results add to the literature in neurosciences showing that rational decision-making should not be opposed to emotions (see the theory of somatic markers Damasio, 1994).

Our findings also strongly support the importance of tax morale and justify incorporating moral dimensions in the standard models of tax compliance. Indeed, when the subjects receive a feedback on their report audit, controlling for the proportion of evaded income, we find a strong physiological impact of the public display of the evaders' pictures on the emotional arousal in addition to monetary sanctions. This may explain that when they are in an environment where nonmonetary sanctions coexist with monetary sanctions the subjects are less likely to cheat and when they do, they evade less. Furthermore, while monetary fines increase later evasion, showing the tax evaders' picture has the opposite effect. The selfreports reveal that both monetary and non-monetary sanctions raise negative emotions. In contrast, learning that their report has not been audited generates positive feelings in evaders, probably due to the conjunction of relief and the joy of getting higher earnings than if they had complied. 
There are reasons for caution in extrapolating these results. In particular, students may not be representative of taxpayers and the size of our sample is relatively small. We have also used audit probabilities that are above the average enforcement values and we cannot measure how various audit probabilities would have changed decisions and emotions (which would be an interesting extension of our paper). Moreover, cheating in our experiment may not be considered as bad as in a real setting since more cheating may lower the audit probability of other players. One can, however, be relatively confident in the external validity of our results because if one observes that emotions arise even in the sterile environment of the laboratory with small monetary stakes, such high audit probabilities leading to frequent audits, and positive immediate externalities in the laboratory, they should be even greater when a yearly income is at stake in actual reporting decisions, with less frequent audits and negative externalities. Indeed, we have found that the first time a subject evades taxes, his emotions are stronger and more negative when he receives a feedback on being audited, while observing frequently one's own picture affects emotional arousal negatively. One can also suspect that when cheating hurts directly other members in a group, as if the product of taxes was immediately redistributed among the taxpayers, emotions would probably be stronger. Therefore, we hope to have contributed to identify some relationships between emotions, sanctions, and cheating.

A limitation is that our methodology does not allow us to identify the very nature of emotions. We can, however, suggest interpretations. Since higher SCR measured at the time of decision is associated with a higher probability to cheat and to a larger deception, this may be due both to the cheater's anxiety related to the risk of deterrence and to the anticipated excitement of earning more money if not detected, and anticipated negative emotions if detected. The emotions experienced after a 
positive audit in the benchmark treatment are probably associated with private emotions such as guilt, regret, or anger, whereas those experienced in the picture treatment may be associated with public emotions such as shame or embarrassment.

One can suggest two main directions for further research. First, regarding economic modeling, the emotional costs and benefits of cheating should be included in the individual's utility function in interaction with its expected monetary return. With the public exposure of deception, people evade less. Since we held the expected monetary return from evasion constant across treatments, this suggests that the net emotional cost of deception has been increased. An interpretation is that when the net cost of anticipated and anticipatory emotions increases, people evade less. Brain imaging could help in measuring these emotional costs and benefits with a distinction -if relevant- between the emotional costs associated with risk-taking and the emotional cost associated with norm violation.

A second direction for research is related to institutional design. We have found that, ceteris paribus, being in an environment where deception is made public reduces by $8.20 \%$ the probability to cheat; for the evaders, it reduces by 3.88 points the proportion of evaded income although by design the non-monetary sanction does not depend on the amount evaded. In contrast, while being audited reduces the proportion of evaded income by 2.92 points, we observe that the higher the fine, the higher the dissimulation of income in the following period. This suggests that a policy threatening to denounce cheaters publicly with a reduced amount of fines -i.e. augmenting the emotional cost and reducing the monetary cost- might be more effective. Further research is however needed to explore the potential backfiring effects of a public exposure of deception. Indeed, once their reputation is lost, evaders may react by evading even more. We have found that frequent exposure 
raises more negative feelings but it also reduces the emotional arousal in case of an audit and overall we do not observe in the Picture treatment an increase of compliance over time. It would be useful to manipulate experimentally the duration of social sanctions to see whether reintegrative shaming -i.e. offering an opportunity to restore reputation- circumvents the potential backfiring effects of these sanctions. 


\section{REFERENCES}

Allingham, M., A. Sandmo (1972). "Income Tax Evasion: A Theoretical Analysis", Journal of Public Economics 1(3-4), 323-338.

Alm, J. (1991). "A Perspective on the Experimental Analysis of Taxpayer Reporting", The Accounting Review 66(3), 577-593.

Alm, J., G.H. McClelland, and W.D. Schulze (1992). "Why do people pay taxes?", Journal of Public Economics 48, 21-48.

Alm, J., B. Jackson, M. McKee (1992). "Institutional Uncertainty and Taxpayer Compliance", American Economic Review 82(4), 1018-1026.

Alm, J., M.B. Cronshaw, and M. McKee (1993). "Tax Compliance with Endogenous Audit Selection Rules", Kyklos 1, 27-45.

Alm J. and M. McKee (2004). "Tax compliance as a coordination game”, Journal of Economic Behavior and Organization 54(3), 297-312.

Alm J. and M. McKee (2006). "Audit Certainty, Audit Productivity and Taxpayer Compliance", National Tax Journal 59, 801-16.

Anders, S., M. Lotze, and M. Erb (2004). "Brain Activity Underlying Emotional Valence and Arousal: A Response-Related fMRI Study", Human Brain Mapping 23, 200-209.

Andreoni, J., B. Erard, and J. Feinstein (1998). "Tax Compliance", Journal of Economic Literature 36, 818-860.

Baldry, J.C. (1986). "Tax evasion is not a gamble", Economics Letters 22, 333-335.

Ben-Shakar, G., G. Bornstein, A. Hopfensitz, and F. van Winden (2007). "Reciprocity and Emotions in Bargaining: Using Physiological and Self-Report Measures", Journal of Economic Psychology 28, 314-323.

Bernasconi, M., and A. Zanardi (2004). Tax evasion, tax rates, and reference dependence", FinanzArchiv: Public Finance Analysis 60(3), 422-445.

Blumenthal, M., C. Christian, and J. Slemrod (2001). "Do Normative Appeals Affect Tax Compliance? Evidence from a Controlled Experiment in Minnesota", National Tax Journal 54(1), 125-138.

Boucsein, W. (1992). Electrodermal Activity. Plenum Series in Behavioral Psychology and Medicine, Plenum.

Bradley, M.M. (2000). "Emotion and motivation". In Cacioppo, J.T., L.G. Tassinary, and G.G. Berntson (Eds). Handbook of Psychophysiology, Cambridge, MA: Cambridge University Press.

Bradley, M.M. and P.J. Lang (2001). "Measuring emotion: Behavior, feeling and physiology". In Lane, R. and L. Nadel (Eds). Cognitive Neuroscience of Emotion. Oxford: Oxford University Press.

Bradley, M.M., M. Codispoti, B.N. Cuthbert, and P.J. Lang (2001). "Emotion and Motivation I: Defensive and Appetitive Reactions in Picture Processing", Emotion 1, 276-298.

Cason, T.N., and L. Gangadharan (2006). "An experimental study of compliance and leverage in auditing and regulatory enforcement", Economic Inquiry 44(2), 352366.

Charness, G. and U. Gneezy (2003). "Portfolio Choice and Risk Attitudes: An Experiment". Mimeo. 
Charness, G. and M Dufwenberg (2006). "Promises and Partnership", Econometrica 74(6), 1579-1601.

Collins, J.H. and R.D. Plumlee (1991). "The Taxpayer's Labor and Reporting Decision: The Effect of Audit Schemes", The Accounting Review 66, 559-576.

Cowell, F. (1990). Cheating the Government: The Economics of Evasion. Cambridge, MA: MIT Press.

Cummings, R.G., J. Martinez-Vazquez, M. McKee, and B. Torgler (2009). "Tax morale affects tax compliance: Evidence from surveys and artefactual field experiments", Journal of Economic Behavior and Organization 70(3), 447-457.

Damasio, A.R. (1994). Descartes' Error, New York: Avon.

Dawson, M. E., A.M. Schell, and D.L. Filion (2000). “The electrodermal system”. In Cacioppo, J. T., L.G. Tassinary, and G.G. Berntson (Eds.). Handbook of Psychophysiology, 2nd ed., Cambridge: Cambridge University Press.

Dhami, S., and A. Al-Nowaihi (2007). "Why do people pay taxes? Prospect theory versus expected utility theory", Journal of Economic Behavior and Organization 64(1), 171-192.

Edelberg, R. (1967). "Electrical properties of the skin". In Brown, C.C. (Ed.). Methods in Psychophysiology. Baltimore: Williams \& Wilkins.

Elster, J. (1996). "Rationality and the Emotions", The Economic Journal 106(438), 1386-1397.

Fortin, B., G. Lacroix, and M.C. Villeval (2007). "Tax Evasion and Social Interactions", Journal of Public Economics 91 (11-12), 2089-2112.

Gerschlager, C. (Ed.) (2005). Deception in Markets: An Economic Analysis. Palgrave Macmillan.

Gneezy, U. (2005). "Deception: The role of consequences", American Economic Review 95(1), 384-394.

Greiner B. (2004). An Online Recruitment System for Economic Experiments. In: K. Kremer, V. Macho (Eds), Forschung und wissenschaftliches Rechnen 2003.

GWDG Bericht 63; Göttingen: Ges. für Wiss. Datenverarbeitung; 2004. p. 79-93.

Halla M. and F.G. Schneider (2009). Taxes and Benefits: Two Distinct Options to Cheat on the State? Research paper, IZA.

Harbaugh, W.T., U. Mayr, and D.R. Burghart, (2007). "Neural Responses to Taxation and Voluntary Giving Reveal Motives for Charitable Donations". Science 316, 1622-1625.

Kahneman, D. and D. Miller (1986). "Norm theory: Comparing reality to its alternatives", Psychological Review 93, 136-153.

Kirchler, E. (2007). The Economic Psychology of Tax Behaviour. Cambridge: Cambrigde University Press.

Lang, P.J., M.M. Bradley, and B.N. Cuthbert (1992). "A motivational analysis of emotion: reflex-cortex connections", Psychological Science 3, 44-49.

Loewenstein, G. (2000). "Emotions in Economic Theory and Economic Behavior", American Economic Review 90(2), 426-432.

Loewenstein, G.F., C.K. Hsee, E.U. Weber, and N. Welch (2001). "Risk as Feelings", Psychological Bulletin 127, 267-286. 
Mehrabian, A. and J.A. Russell (1974). Approach to Environmental Psychology. Cambridge: MIT Press.

Miller, J. O. and K. Low (2001). "Motor processes in simple, go/no-go, and choice reaction time tasks: a psychophysiological analysis", Journal of Experimental Psychology 27(2), 266-289.

Myles, G.D. and R.A. Naylor (1996). "A Model of Tax Evasion with Group Conformity and Social Customs", European Journal of Political Economy 12(1), 49-66.

de Quervain, D.J.F., U. Fischbacher, V. Treyer, M. Schellhammer, U. Schnyder, A. Buck, and E. Fehr (2004). "The Neural Basis of Altruistic Punishment", Science 305, 1254-1258.

Rubinstein A. (2007). "Instinctive and Cognitive Reasoning: A Study of Response Times", Economic Journal 117(523), 1243-1259.

Russell, J.A. and A. Mehrabian (1977). "Evidence for a three-factor theory of emotions", Journal of Research in Personality 11, 273-294.

Sanchez-Pages, S. and M. Vorsatz (2007). "An Experimental Study of Truth-Telling in Sender-Receiver Game", Games and Economic Behavior 61(1), 86-112.

Seiter, J.S. and J. Bruschke (2007). "Deception and Emotion: The Effects of Motivation, Relationship Type, and Sex on Expected Feelings of Guilt and Shame Following Acts of Deception in United States and Chinese Samples". Communication Studies, 58(1), 1-16.

Slemrod, J. (1998). "On voluntary compliance, voluntary taxes, and social capital", National Tax Journal LI, 485-492.

Slemrod, J. (2007). "Cheating Ourselves: The Economics of Tax Evasion”, Journal of Economic Perspectives 21(1), 25-48.

Spicer, M.W. and J.E. Thomas (1982). "Audit probabilities and the tax evasion decision: An experimental approach", Journal of Economic Psychology 2, 241245.

Torgler, B. (2007). Tax Compliance and Tax Morale. A Theoretical and Empirical Analysis. Cheltenham: Edward Elgar.

U.S. Department of the Treasury, Internal Revenue Service. (2006). Updated Estimates of the TY 2001 Individual Income Tax Underreporting Gap. Overview. Washington, D.C.: Office of Research, Analysis and Statistics.

Wild, B. (2003). "Are emotions contagious? Evoked emotions while viewing emotionally expressive faces: quality, quantity, time course and gender differences". Psychiatry Research, 102(2), 109-124.

van Winden, F., M. Krawczyk, and A. Hopfensitz (2008). "Investment, Resolution of Risk, and the Role of Affect". Amsterdam, CREED Working Paper.

Yitzhaki, S. (1974). A note on 'Income Tax Evasion: A Theoretical Analysis', Journal of Public Economics 3(2), 201-202.

Zajonc, R.B. (1984). "The primacy of affect", American Psychologist 39(2), 117-123.

Zeiliger, R. (2000). "A Presentation of Regate", Internet-Based Software for ExperimentalEconomics,http://www.gate.cnrs.fr/ zeiliger/regate/RegateIntro.ppt. Lyon: GATE. 
Table 1. Summary statistics

\begin{tabular}{|c|c|c|c|}
\hline & $\begin{array}{c}\text { Benchmark } \\
\text { treatment }\end{array}$ & $\begin{array}{l}\text { Picture } \\
\text { treatment }\end{array}$ & All treatments \\
\hline Proportion of evaders & $78.06(41.42)$ & $67.22(46.97)$ & $72.64(44.60)$ \\
\hline when income is 50 & $51.67(50.11)$ & $37.78(48.62)$ & $44.72(49.79)$ \\
\hline when income is 100 & $76.67(42.41)$ & $56.11(49.76)$ & $66.39(47.30)$ \\
\hline when income is 150 & $89.44(30.81)$ & $82.22(38.34)$ & $85.83(34.92)$ \\
\hline when income is 200 & $94.44(22.97)$ & $92.78(25.96)$ & $93.61(24.49)$ \\
\hline Proportion of evaded income by evaders & $50.34(30.87)$ & $48.11(31.02)$ & $49.31(30.94)$ \\
\hline when income is 50 & $69.16(38.13)$ & $78.32(33.18)$ & $73.03(36.30)$ \\
\hline when income is 100 & $45.71(30.52)$ & $48.03(33.70)$ & $46.69(31.86)$ \\
\hline when income is 150 & $46.12(28.42)$ & $38.34(26.66)$ & $42.39(27.82)$ \\
\hline when income is 200 & $47.80(24.81)$ & $44.53(23.88)$ & $46.18(24.37)$ \\
\hline Proportion of punished subjects & $37.92(48.55)$ & $35.56(47.90)$ & $36.74(48.23)$ \\
\hline Amount of taxes & $55.11(30.22)$ & $58.18(29.64)$ & $56.65(29.96)$ \\
\hline Amount of fines & $7.39(5.55)$ & $7.06(5.38)$ & $7.23(5.46)$ \\
\hline Payoffs & $67.08(39.21)$ & $64.31(36.78)$ & $65.70(38.03)$ \\
\hline Emotions: SCR-decision in $\mu$ Siemens & $0.16(0.27)$ & $0.15(0.25)$ & $0.16(0.26)$ \\
\hline Non-evaders & $0.09(0.17)$ & $0.09(0.22)$ & $0.09(0.21)$ \\
\hline Evaders & $0.18(0.29)$ & $0.17(0.26)$ & $0.18(0.27)$ \\
\hline Emotions: SCR - audit in $\mu$ Siemens & $0.13(0.27)$ & $0.13(0.25)$ & $0.13(0.26)$ \\
\hline Non-evaders & $0.05(0.19)$ & $0.04(0.11)$ & $0.05(0.15)$ \\
\hline Evaders & $0.15(0.28)$ & $0.17(0.29)$ & $0.16(0.29)$ \\
\hline Decision time in seconds & $12.68(7.76)$ & $10.42(5.73)$ & $11.55(6.91)$ \\
\hline Non-evaders & $9.73(5.92)$ & $8.92(5.57)$ & $9.25(5.72)$ \\
\hline Evaders & $13.51(8.02)$ & $11.15(5.66)$ & $12.42(7.12)$ \\
\hline \multicolumn{4}{|l|}{$\begin{array}{l}\text { Self-reported emotional arousal: from } 1 \\
\text { (extremely weak) to } 7 \text { (extremely strong) }\end{array}$} \\
\hline $\begin{array}{l}\text { Non-evaders } \\
\text { Nontremery strong) }\end{array}$ & $3.91(1.70)$ & $3.90(1.81)$ & $3.90(1.75)$ \\
\hline $\begin{array}{l}\text { Non-evaders } \\
\text { Evaders }\end{array}$ & $3.15(1.80)$ & $3.08(1.78)$ & $3.11(1.79)$ \\
\hline Self-reported hedonic valence: from 1 & $4.12(1.61)$ & $4.30(1.69)$ & $4.20(1.65)$ \\
\hline \multicolumn{4}{|l|}{ (extremely negative) to 7 (extremely positive) } \\
\hline Non-evaders & $3.97(1.66)$ & $3.94(1.72)$ & $3.96(1.69)$ \\
\hline \multirow{2}{*}{ Evaders } & $4.32(1.32)$ & $4.24(1.32)$ & $4.27(1.32)$ \\
\hline & $3.87(1.74)$ & $3.80(1.87)$ & $3.84(1.80)$ \\
\hline Number of observations & 720 & 720 & 1440 \\
\hline Percentage of males & & 62.50 & \\
\hline Average amount invested in the lottery (/15) & & $9.38(3.58)$ & \\
\hline \multicolumn{4}{|l|}{ Percentage of negative sentiments regarding: } \\
\hline Shopkeepers evading taxes & & $54.17(49.84)$ & \\
\hline Contraveners with highway code & & $85.42(35.31)$ & \\
\hline Fare dodgers & & $50.00(50.02)$ & \\
\hline
\end{tabular}

Note: The Table indicates average values; the standard deviations are in parentheses. 
Table 2. Determinants of the proportion of evaded income (Heckman model)

\begin{tabular}{|c|c|c|c|}
\hline & \multirow[t]{2}{*}{$\begin{array}{l}\text { Probability to evade } \\
\text { (Random-effects Probit } \\
\text { model) }\end{array}$} & \multicolumn{2}{|c|}{$\begin{array}{c}\text { Proportion of evaded income (random- } \\
\text { effects GLS models with } \\
\text { robust standard errors) }\end{array}$} \\
\hline & & $(2)$ & (3) \\
\hline Income $=50$ (reference) & - & - & - \\
\hline Income $=100$ & $0.679 * * *(0.124) 0.128$ & $-17.823 * * *(3.531)$ & $-19.008 * * *(3.819)$ \\
\hline Income $=150$ & $1.635 * * *(0.143) 0.245$ & $-18.930 * * *(4.788)$ & $-20.733 * * *(5.250)$ \\
\hline Income $=200$ & $2.265 * * *(0.173) 0.307$ & $-15.528 * * *(5.218)$ & $-17.372 * * *(5.710)$ \\
\hline Picture treatment & $-0.361 * * *(0.111)-0.082$ & $-3.881 * *(1.536)$ & $-3.466 * *(1.625)$ \\
\hline Time trend & $0.001(0.006)<0.001$ & $-0.117(0.085)$ & $-0.156 *(0.089)$ \\
\hline SCR amplitude & $0.612 *(0.351) 0.139$ & $6.717 * *(3.388)$ & $9.002 * *(4.191)$ \\
\hline SCR amplitude * picture $\mathrm{Tr}$. & $-0.631(0.438)-0.143$ & $-2.004(4.435)$ & $-2.921(5.178)$ \\
\hline Decision time & $0.077 * * *(0.020) 0.018$ & $-0.857 * * *(0.253)$ & $-1.416 * * *(0.395)$ \\
\hline Decision time $^{2}$ & $-0.001 * *(<0.001)<-0.001$ & $0.007 *(0.004)$ & $0.022 * *(0.009)$ \\
\hline Investment in the lottery & $0.045(0.046) 0.010$ & $0.956(0.712)$ & $0.924 * *(0.421)$ \\
\hline Male & $0.191(0.336) 0.044$ & $18.468 * * *(4.692)$ & $15.825 * * *(3.159)$ \\
\hline Age & $-0.063 * * *(0.019)-0.014$ & $-0.232(0.406)$ & $-0.029(0.337)$ \\
\hline First time evasion & - & - & $-12.065(10.277)$ \\
\hline Audit in $t-1$ & - & - & $-2.922 *(1.624)$ \\
\hline Amount of the fine in $t-1$ & - & - & $0.724 * * *(0.162)$ \\
\hline Mother with university educ. & - & - & $-8.879 * * *(3.261)$ \\
\hline Loan for paying studies & - & & $8.661 * *(3.381)$ \\
\hline Negative opinion on: & & - & \\
\hline *Shopkeepers evading taxes & - & - & $4.060(3.298)$ \\
\hline *Contraveners with highway code & - & - & $-15.171 * * *(4.811)$ \\
\hline *Fare dodgers & - & - & $-5.309(3.382)$ \\
\hline Inverse Mill's ratio & - & $3.391(5.894)$ & $1.503(6.381)$ \\
\hline Constant & $0.250(0.607)$ & $57.015 * * *(11.241)$ & $77.091 * * *(10.413)$ \\
\hline Number of observations & 1440 & 1046 & 1003 \\
\hline Log likelihood & -515.982 & - & - \\
\hline Wald $\chi^{2}$ & 313.36 & 174.23 & 366.98 \\
\hline Prob $>\chi^{2}$ & 0.000 & 0.000 & 0.000 \\
\hline$\rho$ & $0.489 * * *$ & 0.372 & 0.131 \\
\hline $\mathrm{R}^{2}$ & - & 0.301 & 0.394 \\
\hline
\end{tabular}

Note: Standard errors are in parentheses and the marginal effects of the coefficients in the Probit model are in italics. *,**, and *** indicate statistical significance at the $0.10,0.05$, and 0.01 level, respectively. 
Table 3. Determinants of the SCR amplitude and of the level of affective self-reports when receiving a feedback on audit

\begin{tabular}{lccc}
\hline Dependent variables & $\begin{array}{c}\text { SCR amplitude } \\
\text { RE Tobit model } \\
(1)\end{array}$ & $\begin{array}{c}\text { Self-reported } \\
\text { emotional arousal } \\
\text { Ordered Probit }(2)\end{array}$ & $\begin{array}{c}\text { Self-reported } \\
\text { Hedonic valence } \\
\text { Ordered Probit }(3)\end{array}$ \\
\hline Period & $-0.001(0.003)$ & $0.035^{* * *}(0.010)$ & $0.017^{* *}(0.007)$ \\
Proportion of evaded income & $0.001^{*}(<0.001)$ & $<0.001(0.002)$ & $<-0.001(0.001)$ \\
First time evasion & $0.179^{* * *}(0.066)$ & $-0.288^{* * *}(0.111)$ & $-0.335^{* *}(0.153)$ \\
Non audited evader & $0.106^{* * *}(0.035)$ & $0.595^{* * *}(0.123)$ & $1.201^{* * *}(0.165)$ \\
First time audit & $0.301^{* * *}(0.067)$ & $0.503^{* * *}(0.127)$ & $0.186(0.169)$ \\
Amount of the fine & $0.011^{* * *}(0.004)$ & $0.032^{* *}(0.016)$ & $-0.065^{* * *}(0.017)$ \\
Display of own picture & $0.133^{* * *}(0.040)$ & $0.570^{* * *}(0.120)$ & $-0.447^{* * *}(0.127)$ \\
First time own picture & $0.298^{* * *}(0.067)$ & $0.114(0.107)$ & $-0.072(0.150)$ \\
Current number of times own & $-0.021^{*}(0.011)$ & $-0.148^{* * *}(0.056)$ & $-0.077^{* * *}(0.033)$ \\
picture & $-0.181^{* * *}(0.043)$ & - & - \\
Constant & 1440 & 1440 & - \\
\hline Nb observations & $777(53.96)$ & - & - \\
Nb left-censured obs. (\%) & -747.416 & $(-2600.902)$ & $(-2326.374)$ \\
Log (pseudo) likelihood & 171.20 & 73.35 & 126.18 \\
Wald $\chi^{2}$ & 0.000 & 0.000 & 0.000 \\
Prob $>\chi^{2}$ & $0.166^{* * *}$ & - & - \\
$\rho$ & - & 0.028 & 0.142 \\
Pseudo $\mathrm{R}^{2}$ & - & & \\
\hline
\end{tabular}

Note: Models 2 and 3 use robust standard errors and clustering at the individual level. ${ }^{*}$ and ${ }^{* * *}$ indicate statistical significance at the 0.10 and 0.01 level, respectively. The SCR values lie between 0 and 2.129. The self-reported emotional arousal variable can take any integer value between 1 (extremely low) and 7 (extremely high). The hedonic valence variable is coded from 1 (extremely negative) to 7 (extremely positive). 
Appendix. The physionomics laboratory and the skin conductance data analysis

Experimental sessions took place in a noiseless room with stable temperature set to $21^{\circ} \mathrm{C}$. Skin conductance activity was recorded with a BIOPAC MP150W system and two TEL100C telemetry modules (BIOPAC Systems, EU). Two Ag/AgCl electrodes filled with $0.5 \%$ saline in a neutral-base paste were placed on the subject's distal phalanges of the middle and the index fingers of the non-dominant hand, after the attachment site had been cleaned with a neutral soap (Dawson et al., 2000). A constant voltage of $0.5 \mathrm{~V}$ was applied between the electrodes. The skin conductance signal was amplified (x 2000) and low-pass filtered (30 Hz) before being sampled at $125 \mathrm{~Hz}$. Skin conductance activity was continuously recorded until the end of the session.

Regarding the skin conductance analysis, the skin conductance signal was low-pass filtered at $0.5 \mathrm{~Hz}$ offline, using a fifth-order Butterworth low-pass digital filter. Skin Conductance Responses (SCR) onset and peak were automatically detected, when the first derivative of the filtered signal changed sign, by a routine written in Matlab (The MathWorks Inc., USA). Onsets were identified by a negative to positive zero crossing, while peaks were identified by a positive to negative zero crossing. The SCR amplitude was calculated as the difference between the signal amplitude at the peak and the onset times. The SCR amplitude was thresholded at $0.02 \mu \mathrm{S}$ (Dawson et $a l ., 2000)$. The whole signal was visually inspected prior to further analysis and false SCR detections were removed. The detection of an accelerative deflection during the interval between onset and peak times indicated SCRs overlapping during rise time. In that case, the two SCRs were $i$ ) separated, if they could be related to different events (according to the epochs defined below), or $i$ ) summed together, if they were related to a single event (see Boucsein, 1992). In the case of responses overlapping during recovery time, Edelberg (1967) has shown that the amplitude scoring based on the difference between the signal amplitude at the peak and the onset times is sufficiently accurate and it is used as a standard procedure. In order to minimize SCR overlapping between events of interest, we imposed a minimum interval between events of six seconds.

In long-term exosomatic continous current recording, skin conductance signal may show a downward drift that is usually associated to a progressive polarization of electrodermal electrodes (Edelberg, 1967). An adequate correction of drift is only possible when calibration values are recorded during the signal acquisition and it is not an imperative pre-processing procedure for short-term recordings (Boucsein, 1992). For that reason, SCR amplitudes were not corrected for electrodermal activity drift in our analysis. SCR habituation effect was balanced across treatments since every treatment had the same number of periods. The habituation effect was further accounted within the regression model by the introduction of time as confound. SCRs were analyzed for the decision, the feedback on audit and the feedback on payoff events. SCRs with onset between 1.0 and $3.0 \mathrm{~s}$ after the beginning of an audit or payoff were assumed specific to the event. With respect to the decision event, given its self-paced duration, SCRs were allowed onset time from $1.0 \mathrm{~s}$ after the subject is informed on his income until his decision. Indeed, we are especially interested in measuring the intensity of emotions before the subject makes his reporting decision, because it should capture the emotional content of the subject's deliberation. 